\title{
The role of perioperative warming in surgery: a systematic review
}

\section{0 papel do aquecimento perioperatório em cirurgia: uma revisão sistemática}

\author{
Muhammad Shafique Sajid ${ }^{1}$, Ali Jabir Shakir ${ }^{2}$, Kamran Khatri ${ }^{3}$, Mirza Khurrum Baig ${ }^{4}$ \\ Department of Colorectal Surgery, Worthing Hospital, Worthing, West Sussex, United Kingdom
}

\section{KEY WORDS:}

Body temperature regulation. Hypothermia.

Blood loss, surgical.

Shivering.

Wound infection.

\section{PALAVRAS-CHAVE:}

Regulação da temperatura corporal.

Hipotermia.

Perda sanguínea cirúrgica.

Tremor por sensação de frio Infecção dos ferimentos.

\section{ABSTRACT}

OBJECTIVE: The objective of this review was to systematically analyze the trials on the effectiveness of perioperative warming in surgical patients. METHODS: A systematic review of the literature was undertaken. Clinical trials on perioperative warming were selected according to specific criteria and analyzed to generate summative data expressed as standardized mean difference (SMD).

RESULTS: Twenty-five studies encompassing 3,599 patients in various surgical disciplines were retrieved from the electronic databases. Nineteen randomized trials on 1785 patients qualified for this review. The no-warming group developed statistically significant hypothermia. In the fixed effect model, the warming group had significantly less pain and lower incidence of wound infection, compared with the no-warming group. In the random effect model, the warming group was also associated with lower risk of post-anesthetic shivering. Both in the random and the fixed effect models, the warming group was associated with significantly less blood loss. However, there was significant heterogeneity among the trials.

CONCLUSION: Perioperative warming of surgical patients is effective in reducing postoperative wound pain, wound infection and shivering. Systemic warming of the surgical patient is also associated with less perioperative blood loss through preventing hypothermia-induced coagulopathy. Perioperative warming may be given routinely to all patients of various surgical disciplines in order to counteract the consequences of hypothermia.

\section{RESUMO}

OBJETIVO: 0 objetivo desta revisão é analisar sistematicamente os ensaios sobre a eficácia do aquecimento perioperatório em pacientes cirúrgicos. MÉTODOS: Uma revisão sistemática da literatura foi realizada. Ensaios clínicos sobre aquecimento perioperatório foram selecionados segundo critérios específicos e analisados para gerar dados sumativo expresso na diferença média padronizada (standardized mean difference, SMD).

RESULTADOS: Vinte e cinco estudos englobando 3.599 pacientes de várias disciplinas de cirurgia foram obtidos a partir de bases de dados eletrônicas. Dezenove ensaios aleatórios em 1.785 pacientes qualificados para esta revisão. Nenhum grupo de aquecimento desenvolveu estatisticamente significativa hipotermia. No modelo de efeito fixo, grupo de aquecimento tiveram significativamente menos dor e menor incidência de infecção na ferida quando comparado com o grupo de não-aquecimento. No modelo de efeito aleatório, grupo de aquecimento também foi associado a um menor risco de tremores pós-anestesia. Em ambos os modelos de efeitos fixos e aleatórios, o aquecimento foi significativamente associado com menor perda de sangue. No entanto, houve significativa heterogeneidade entre os ensaios.

CONCLUSÃ0: 0 aquecimento perioperatório de pacientes cirúrgicos é eficaz na redução da dor pós-operatória ferida, infecção ferida, e tremores. 0 aquecimento sistêmico do paciente cirúrgico também está associado com menor perda de sangue no perioperatório prevenindo hipotermia e induzindo coagulopatia. 0 aquecimento perioperatório pode ser administrado rotineiramente a todos os pacientes cirúrgicos de diversas disciplinas, a fim de neutralizar as consequências da hipotermia.
${ }^{1}$ MBBS, MBA, MD, MSC, FRCS. Specialist Registrar in General \& Colorectal Surgery, Department of Colorectal Surgery, Worthing Hospital, Worthing, West Sussex, United Kingdom. ${ }_{2}^{2}$ MBBS, FRCS. Specialty Surgeon in General \& Colorectal Surgery, Department of Colorectal Surgery, Worthing Hospital, Worthing, West Sussex, United Kingdom. ${ }^{3}$ MBBS, MRCS. Senior House Officer in General \& Colorectal Surgery, Department of Colorectal Surgery, Worthing Hospital, Worthing, West Sussex, United Kingdom. ${ }^{4}$ MBBS, MD, FRCS. Consultant Surgeon in the Department of Colorectal Surgery, Worthing Hospital, Worthing, West Sussex, United Kingdom. 


\section{Introduction}

Hypothermia, defined as core temperature below $36{ }^{\circ} \mathrm{C}^{1-3}$ is common in operating theaters and has often been disregarded as an inevitable consequence of general anesthesia and surgery. ${ }^{2,4,5}$ The body's core temperature is determined by the balance between heat loss and heat gain. Exposure to a cold operating theater environment and anestheticinduced impairment of thermoregulatory control are two of the commonest contributing factors that tip the balance in favor of heat loss, thereby leading to hypothermia in surgical patients. ${ }^{1,6}$

Hypothermia confers distinct benefits as well as severe complications in surgical patients. The potential benefits include protection against the deleterious effects of cerebral ischemia and malignant hyperthermia. ${ }^{7}$ However, hypothermia may increase susceptibility to perioperative wound infection by causing vasoconstriction and impaired immunity. Vasoconstriction decreases the partial pressure of oxygen in tissue, which lowers the resistance to infection. ${ }^{8}$ The other commonly known adverse effects of hypothermia include shivering, ${ }^{9}$ prolonged duration of drug action, ${ }^{10}$ coagulopathy, ${ }^{11}$ myocardial ischemia and decreased resistance to surgical infections. ${ }^{12}$ Perioperative warming has been shown to reduce perioperative complications. ${ }^{13,14}$ Several prophylactic and therapeutic measures have been tried with the aim of reducing or abolishing the development of perioperative hypothermia. Various perioperative warming techniques like simple cotton blankets, carbon-fiber sheets, circulating hot water mattresses, forced air warming, warm fluid infusion and esophageal heat exchange systems ${ }^{9,15,16}$ are in use in all surgical disciplines. These perioperative warming systems are being used during the preoperative, intraoperative and postoperative phases with variable efficacy. The duration of perioperative warming is also under review and prolonged exposure of surgical patients to warming systems has proven to be quite effective in major elective abdominal surgery. ${ }^{17}$

The aim of this systematic review was to compare the efficacy of perioperative warming of surgical patients aimed at reducing the con-

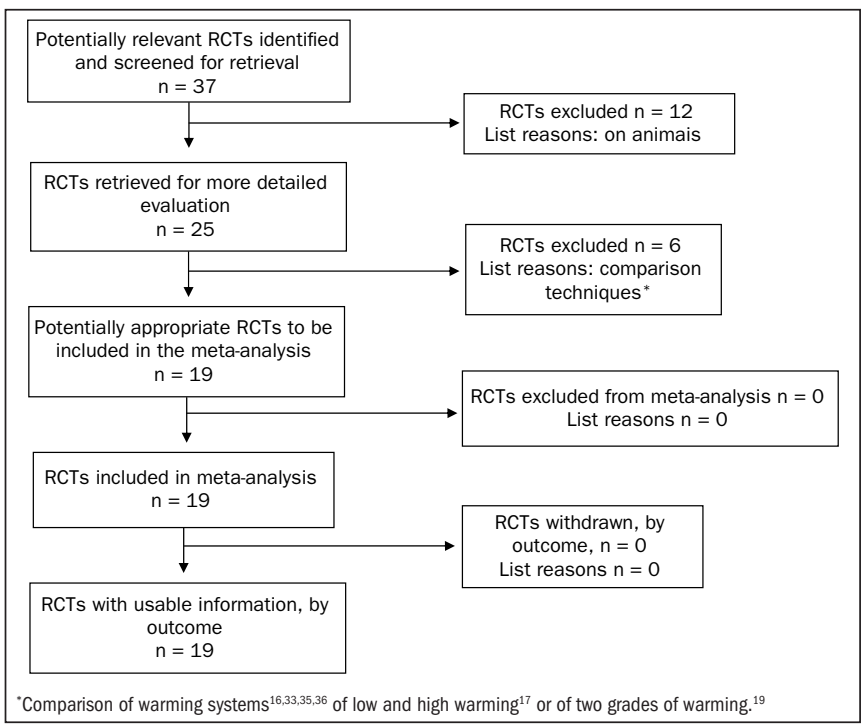

Figure 1. Quality of Reporting of Meta-Analyses (QUORUM) diagram template used in this review and results from the retrieval of randomized controlled trials (RCT). sequences of wound infection, coagulopathy, blood loss, postoperative pain and postoperative shivering, in relation to no warming.

\section{Methods}

Relevant prospective randomized controlled trials on perioperative warming among surgical patients published between January 1980 and June 2007 were identified through the Medical Literature Analysis and Retrieval System Online (Medline), Excerpta Medica (Embase), Cumulative Index to Nursing and Allied Health Literature (CINAHL), Cochrane library and Pubmed databases. The search strategy for target articles was not limited by time, age or gender. However, through frequent and thorough searching, it was noticed that there were no published comparative, non-randomized or randomized trials in the literature before 1980. The terms "randomized trials on perioperative warming", "trials on perioperative warming" and "warming in surgical patients" were used in combination with the headings "surgical patients", "forced air warming", "thermoregulation in anesthetized patients" and "warming blankets". Relevant articles referenced in these publications were obtained. The "related article" function was also used to widen the search criteria. All abstracts, comparative studies, randomized trials, non-randomized trials and citations that were firstly scanned through were reviewed comprehensively in accordance with the Quality of Reporting of Meta-analyses (QUORUM) template for the literature search. Each article was critically reviewed to assess its eligibility for inclusion or exclusion in this review.

Statistical analysis was performed by a senior statistician, using the Statistics for Windows software in Microsoft Excel $2007^{\circledR}$. The methods used were Hedges $G$ statistic for the calculation of standardized mean difference (SMD), the inverse variance method for the fixed effect model and the DerSimonian/Laired method for the random effect model. The estimate of the difference between the two techniques was pooled depending on the effect weights in the results, which were determined by the variance in each trial estimate. Forest plots were used for graphical displays of results from the meta-analysis: the square around the estimate represents the accuracy of the estimation (sample size) and the line represents the $95 \%$ confidence interval.

\section{Results}

Twenty-five studies encompassing 3,599 patients in various surgical disciplines were retrieved from the electronic databases. Nineteen randomized controlled trials ${ }^{11-12,14,18-32}$ on 1,785 patients qualified for this review in accordance with the inclusion criteria (Figure 1). Six trials ${ }^{16,17,33-36}$ were excluded for the reasons mentioned in Figure 1. The characteristics of the trials included are given in Table $1 .{ }^{11,12,14,18-32}$

\section{Methodological quality of studies included}

The characteristics of the trials included are explained comprehensively in Table 2 for methodological quality analysis. ${ }^{11,12,14,18-32}$ The Mantel-Haenszel fixed effect model was used to compute robustness and susceptibility to any outlier among these trials. The allocation, concealment and blinding of the investigator or assessor were not clearly reported, and consequently the methodological quality of the trials was con- 
Table 1. Characteristics of included trials

\begin{tabular}{|c|c|c|c|c|}
\hline Trial & Patients & Warming technique & Type of surgery & Outcome measurements \\
\hline Melling and Leaper ${ }^{18}$ & 45 & Non-contact radiant heat system & General surgery & Pain and wound infection \\
\hline Kim et al. ${ }^{19}$ & 40 & Forced warming blanket & Cardiothoracic & Temperature \\
\hline Cavallini et al. ${ }^{20}$ & 76 & Forced warming blanket & Plastic surgery & Temperature, coagulation \\
\hline Zhao et al. ${ }^{21}$ & 40 & Forced warming blanket & Abdominal surgery & $\begin{array}{l}\text { Temperature, blood loss, shivering, } \\
\text { extubation time }\end{array}$ \\
\hline Scheck et al. ${ }^{22}$ & 30 & Carbon-fiber warming blanket & Trauma patients & Temperature \\
\hline Xu et al. ${ }^{23}$ & 40 & $\begin{array}{l}\text { Forced warming blanket and fluid } \\
\text { warming device }\end{array}$ & Abdominal surgery & $\begin{array}{l}\text { Temperature, blood loss, shivering, } \\
\text { extubation time }\end{array}$ \\
\hline Vanni et al. ${ }^{24}$ & 30 & NA & Abdominal surgery & Temperature \\
\hline Persson and Lundberg ${ }^{25}$ & 59 & Forced warming blanket & Gynecological & Temperature, pain \\
\hline Melling et al. ${ }^{14}$ & 421 & Forced warming blanket & General surgery & Wound infection \\
\hline El-Rahmany et al. ${ }^{26}$ & 149 & Forced warming blanket & Cardiothoracic & Temperature, cardiovascular vital signs \\
\hline Bock et al. ${ }^{27}$ & 40 & Forced warming blanket & Abdominal Surgery & $\begin{array}{l}\text { Temperature, blood loss, stay, cost, } \\
\text { transfusion. }\end{array}$ \\
\hline Wongprasartsuk et al. ${ }^{28}$ & 26 & Forced warming blanket & Orthopedic & $\begin{array}{l}\mathrm{O}_{2} \text { consumption, } \mathrm{CO}_{2} \text { production, pain, } \\
\text { temperature }\end{array}$ \\
\hline Frank et al. ${ }^{12}$ & 300 & Forced warming blanket & Vascular, thoracic and abdominal & $\begin{array}{l}\text { Temperature, ischemic heart disease, } \\
\text { cardiac arrest }\end{array}$ \\
\hline Schmied et al. ${ }^{11}$ & 60 & Forced warming blanket & Orthopedics & Blood loss, transfusions \\
\hline Kurz et al. ${ }^{29}$ & 200 & Forced warming blanket & Colorectal surgery & Wound infection, stay \\
\hline Frank et al. ${ }^{30}$ & 74 & Forced warming blanket & Vascular, thoracic and abdominal & $\begin{array}{l}\text { Neuroendocrine response, tempera- } \\
\text { ture, blood pressure, pulse rate }\end{array}$ \\
\hline Frank et al. $^{31}$ & 100 & NA & Vascular surgery & Temperature, cardiac stress \\
\hline Camus et al. ${ }^{32^{*}}$ & 22 & Forced warming blanket & Abdominal Surgery & Temperature, shivering \\
\hline Camus et al. ${ }^{32 \dagger}$ & 33 & Forced warming blanket & Abdominal surgery & Temperature, shivering \\
\hline
\end{tabular}

"limb a of trial; 'limb b of trial. NA = not available. Heating technique was not mentioned in the trial but this group was definitely provided with perioperative warming.

Table 2. The randomized controlled trials included, all of them with stated inclusion and exclusion criteria

\begin{tabular}{|c|c|c|c|c|c|}
\hline Trial & Baseline comparables & Blinding & Technique of randomization & Allocation concealment & $\begin{array}{c}\text { Intention to treat } \\
\text { analysis }\end{array}$ \\
\hline Melling and Leaper ${ }^{18}$ & Stated & Yes & Random number technique & Yes & No \\
\hline Kim et al. ${ }^{19}$ & Stated & No & Sealed envelopes & Yes & No \\
\hline Cavallini et al. ${ }^{20}$ & Stated & No & Random assigning & No & No \\
\hline Zhao et al. ${ }^{21}$ & Stated & No & Not given & No & No \\
\hline Scheck et al. ${ }^{22}$ & Stated & No & Not given & No & No \\
\hline Xu et al..$^{23}$ & Stated & No & Not given & No & No \\
\hline Vanni et al. ${ }^{24}$ & Stated & Yes & Sealed envelopes & Yes & No \\
\hline Melling et al. ${ }^{14}$ & Stated & No & Sealed envelopes & No & Yes \\
\hline Persson and Lundberg ${ }^{25}$ & Stated & No & Not given & No & No \\
\hline El-Rahmany et al. ${ }^{26}$ & Stated & No & Computerized & No & Yes \\
\hline Bock et al. ${ }^{27}$ & Stated & No & Random assigning & No & Yes \\
\hline Wongprasartsuk et al. ${ }^{28}$ & Stated & No & Random assigning & Yes & Yes \\
\hline Frank et al. ${ }^{12}$ & Stated & No & Computerized & No & No \\
\hline Schmied et al. ${ }^{11}$ & Stated & No & Random assigning & Yes & Yes \\
\hline Kurz et al. ${ }^{29}$ & Stated & Yes & Not given & No & No \\
\hline Frank et al. ${ }^{30}$ & Stated & Yes & Computerized & No & No \\
\hline Frank et al. ${ }^{31}$ & Stated & No & Computerized & No & No \\
\hline Camus et al. ${ }^{32}$ & Not stated & No & Not given & No & No \\
\hline
\end{tabular}

$\mathrm{RCT}=$ randomized controlled trial.

sidered inadequate and the results from our review may be considered biased. Heterogeneity (clinical and methodological diversity) was seen among all these trials (Chart 1). Limited availability of data on various outcome variables and lack of a major multicenter double blind randomized controlled trial restricted this review with regard to detailed sub-group analysis. However, a subgroup analysis of trials with clearly reported allocation concealment was performed. We felt that performing sensitivity analysis was not relevant due to limited numbers of studies. We attempted to assess publication bias by using funnel plots, but this was difficult to compute due to the small numbers of patients.

\section{Hypothermia}

Fourteen trials ${ }^{12,20-24,26-32,37}$ contributed towards the combined analysis on the development of hypothermia in the no-warming group. In both the fixed and the random effect models, the no-warming group developed
Chart 1. Causes of heterogeneity

\begin{tabular}{|c|} 
Methodological heterogeneity \\
Different techniques for randomization \\
Lack of blinding in many trials \\
No allocation concealment in many trials \\
Analysis by intention to treat is not stated in all trials \\
Analysis of randomized and non-randomized trials together \\
Clinical heterogeneity \\
Different surgical specialties analyzed together \\
Different outcome variables assessed e.g. stress hormone level \\
Different perioperative warming techniques used \\
Variable follow-up time among trials \\
Non-consistent results from trials
\end{tabular}

statistically significant hypothermia [fixed effect SMD -1.78, 95\% confidence interval, $\mathrm{CI}(-1.96,-1.61), \mathrm{P}=0.0000$, degrees of freedom, $\mathrm{df}=13$, $\mathrm{z}=-20.25$; and random effect SMD $-4.44,95 \%$ CI $(-5.92,-2.95), \mathrm{P}=$ $0.0000, \mathrm{df}=13, \mathrm{z}=-5.92$; Table $3^{12,20-24,26-30,32,37}$ and Figure 2]. 


\section{Postoperative pain}

Two trials ${ }^{18,28}$ contributed towards the combined analysis on postoperative pain. In the fixed effect model, the warming group had significantly less pain [SMD $-1.84,95 \% \mathrm{CI}(-2.45,-1.22), \mathrm{P}=0.0000, \mathrm{df}=1$, $\mathrm{z}=-5.8]$. In the random effect model, this difference was not statistically significant between the two groups [SMD -2.0, 95\% CI $(-4.5,0.46)$, $\mathrm{P}=0.11, \mathrm{df}=1, \mathrm{z}=-1.59$; Table $4^{18,28}$ and Figure 3]. However, there was significant heterogeneity among the trials $(\mathrm{Q}=16.28, \mathrm{P}=0.001)$.

\section{Wound infection}

Three trials ${ }^{14,18,29}$ contributed towards the combined analysis on the postoperative wound infection rate. In the fixed effect model, the warming group was associated with lower risk of developing postoperative wound

Table 3. Temperature changes: combined analysis

\begin{tabular}{|c|c|c|}
\hline & Warming group & Control group \\
\hline Cavallini et al. ${ }^{20}$ & $36 \pm 0.6 \mathrm{C}$ & $34 \pm 1.0$ \\
\hline Zhao et al..$^{21}$ & $36.4 \pm 0.4 \mathrm{C}$ & $35.3 \pm 0.5 C$ \\
\hline Scheck et al..$^{22}$ & $36.4 \pm 0.2 \mathrm{C}$ & $34.7 \pm 0.6 \mathrm{C}$ \\
\hline Xu et al. ${ }^{23}$ & $36.4 \pm 0.4 \mathrm{C}$ & $35.3 \pm 0.5 C$ \\
\hline Vanni et al. ${ }^{24}$ & $34.2 \pm 1.1 \mathrm{C}$ & $34.1 \pm 0.9 \mathrm{C}$ \\
\hline El-Rahmany et al. ${ }^{26}$ & $34.5 \pm 0.1 \mathrm{C}$ & $34.5 \pm 0.1 C$ \\
\hline Bock et al. ${ }^{27}$ & $36.5 \mathrm{C}$ & $35.5 \mathrm{C}$ \\
\hline Wongprasartsuk et al. ${ }^{28}$ & $36.9 \pm 0.55 C$ & $36.2 \pm 0.87 c$ \\
\hline Frank et al. ${ }^{12}$ & $36.7 \pm 0.1 \mathrm{C}$ & $35.4 \pm 0.1 \mathrm{C}$ \\
\hline Kurz et al. ${ }^{29}$ & $36.6 \pm 0.5 C$ & $34.7 \pm 0.6 \mathrm{C}$ \\
\hline Frank et al. ${ }^{30}$ & $36.7 \pm 0.1 \mathrm{C}$ & $35.3 \pm 0.1 C$ \\
\hline Camus et al. ${ }^{32 *}$ & $36.4 \pm 0.1 \mathrm{C}$ & $34.6 \pm 0.3 \mathrm{C}$ \\
\hline Camus et al. ${ }^{32 \dagger}$ & $37.1 \pm 0.1 \mathrm{C}$ & $35.1 \pm 0.2 \mathrm{C}$ \\
\hline Matsuzaki et al. ${ }^{37}$ & $36.9 \pm 0.3 C$ & $36.6 \pm 0.5 \mathrm{C}$ \\
\hline
\end{tabular}

"limb a of trial; †limb b of trial.

Table 4. Postoperative pain: combined analysis

\begin{tabular}{|c|c|c|}
\hline \multicolumn{3}{|c|}{ Mean pain score (Visual Analogue Scale) $0-10 \mathrm{~cm}$} \\
\hline & Warming group & Control group \\
\hline Melling and Leaper ${ }^{18}$ & 2.8 & 4.5 \\
\hline Wongprasartsuk et al. ${ }^{28}$ & 5.7 & 6.1 \\
\hline
\end{tabular}

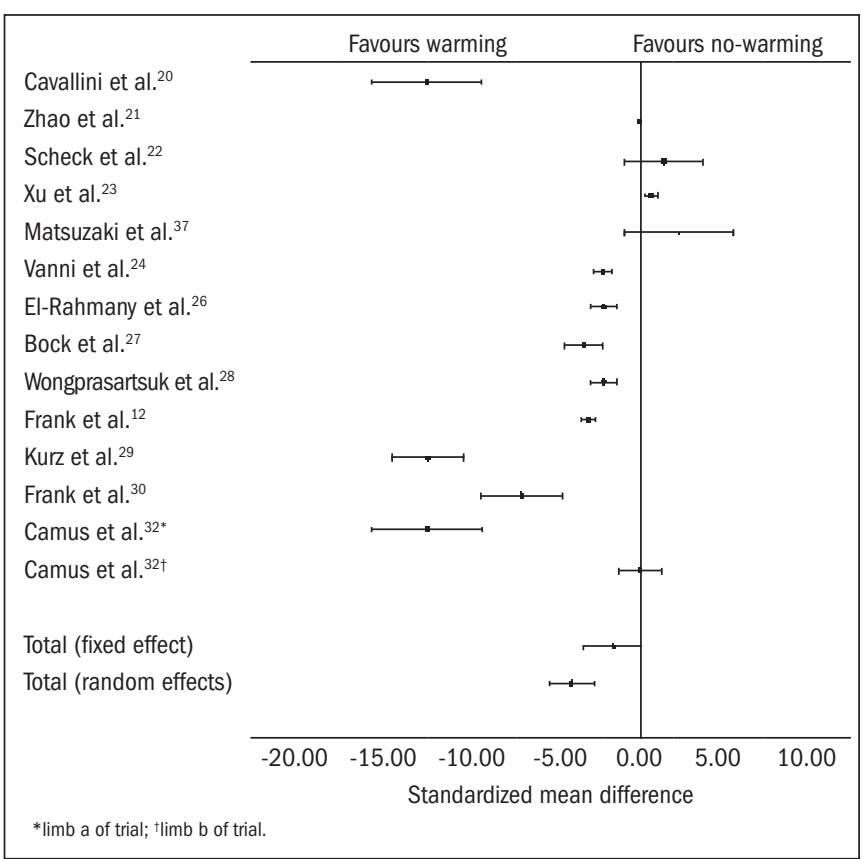

Figure 2. Hypothermia: combined analysis of the randomized controlled trials in the review. infection [SMD 0.32, 95\% CI (0.18-0.56), $\mathrm{P}=0.0001, \mathrm{df}=2, \mathrm{z}=-3.99$; Table $5^{14,18,29}$ and Figure 4], compared with the no-warming group. There was no heterogeneity among the trials $(\mathrm{Q}=0.06, \mathrm{P}=0.96)$.

\section{Shivering}

Five trials $s^{21,23,24,32}$ contributed towards the combined analysis on postoperative shivering. In the random effect model, the warming group was associated with lower risk of post-anesthetic shivering [SMD 0.01, 95\% CI (0.001-0.08), P $=0.0000, \mathrm{df}=4, \mathrm{z}=-4.43$; Table $6^{21,23,24,32}$ and Figure 5], compared with the no-warming group. There was no heterogeneity among the trials $(\mathrm{Q}=0.082, \mathrm{P}=0.9980)$.

\section{Blood loss}

Five trials $s^{11,21,23,25,27}$ contributed towards the combined analysis on perioperative blood loss. Both in the random and in the fixed effect models, the warming group was associated with significantly less blood loss [random effect SMD -1.60, 95\% CI (-1.92, -1.29), P = 0.0000, df = 4, z $=-9.99$; and fixed effect SMD -2.10, 95\% CI (-3.31, -0.89), P = 0.0007, $\mathrm{df}=4, \mathrm{z}=-3.40$; Table $7^{11,21,23,25,27}$ and Figure 6]. However, there was significant heterogeneity among the trials $(\mathrm{Q}=55.77, \mathrm{P}=0.0000)$.

\section{Myocardial dysfunction, coagulopathy and stress hormone imbalance}

There was insufficient data in the trials available to assess hypothermia-induced myocardial dysfunction, coagulopathy and stress hormone imbalance.

\section{Subgroup analysis}

In the subgroup analysis, trials with allocation concealment ${ }^{2,11,19,24,28}$ were analyzed separately. Two trials ${ }^{24,28}$ contributed towards the calcu-

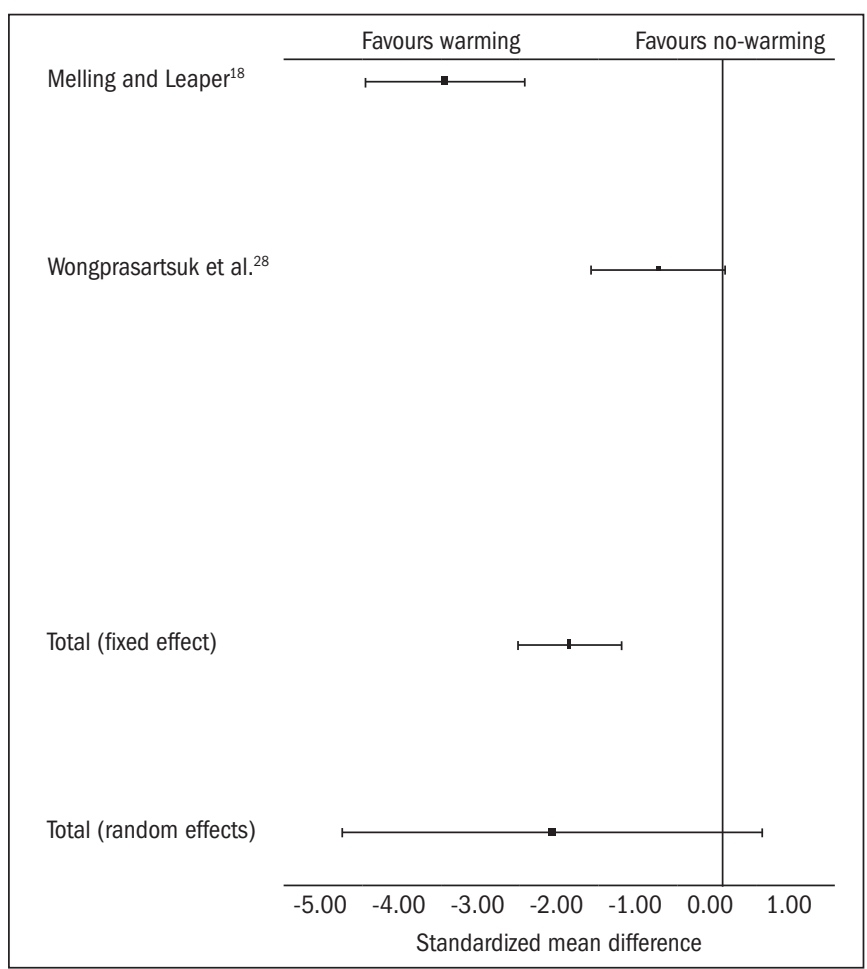

Figure 3. Postoperative pain: combined analysis of the randomized controlled trials in this review. 
lation of hypothermia. The warming group was at less risk of developing hypothermia, compared with the no-warming group $(\mathrm{P}=0.0163)$. Two trials ${ }^{18,28}$ contributed towards the calculation of postoperative pain. The warming group was associated with less postoperative wound pain, compared with the non-warming group $(\mathrm{P}=0.0001)$. The combined calculation of perioperative blood loss, wound infection and postoperative shivering could not be performed because of insufficient data quoted in the trials.

\section{Discussion}

Patients in various surgical disciplines are exposed to numerous factors that may alter thermoregulatory mechanisms and result in postoperative hypothermia, including a cold operating theater, cold intravenous fluids, cold blood transfusions, cold antiseptic skin preparations and anesthesia. ${ }^{1,38,39}$ The latter obliterates behavioral responses and inhibits afferent input, thereby lowering the temperature threshold for thermoregulatory responses to hypothermia and preventing efferent responses. ${ }^{40}$ Some patients are particularly at higher risk of developing hypothermia: the factors involved include surgery lasting for more than two hours, extremes of age, trauma, abdominal surgery, thoracic surgery, massive transfusions of intravenous fluids or blood and massive blood or fluid loss. ${ }^{38,39}$ Inadvertent perioperative hypothermia prolongs the recovery time and also increases blood loss, surgical site infection and total hospital stay. ${ }^{8,39}$

Perioperative skin warming has been shown to reduce the initial postinduction hypothermia, intraoperative hypothermia and postoperative shivering, even for procedures lasting for more than three hours. ${ }^{9}$ Furthermore, a single hour of preoperative skin surface warming has been reported to reduce the rate at which core hypothermia developed during the first hour of anesthesia. ${ }^{33}$ Our analysis shows that the no-warming group is at significant risk of developing perioperative hypothermia, which in turn can give rise to significant perioperative morbidity.

Perioperative systemic warming, in addition to standard forced warm air intraoperative warming, significantly reduces blood loss and complications in patients. ${ }^{17}$ These findings corroborate those from the independent studies of Schmied et al. ${ }^{11}$ and Winkler et al. ${ }^{34}$ In the latter study on blood loss following total hip arthroplasty, even a small difference in median core intraoperative temperature of $0.5^{\circ} \mathrm{C}$ resulted in significantly less blood loss among the patients who were warmed. This excessive blood loss in hypothermic patients is due to hypothermia-induced coagulopathy ${ }^{41,42}$ that results from impaired platelet aggregation and prolonged bleeding time. Bleeding time depends on several variables, including the number and function of platelets, white and red cell counts, vascular factors, hormones and temperature. Although studies have been widely conducted, the bleeding time test does not strictly correlate with surgical bleeding. ${ }^{41,43}$ Nonetheless, with standardized techniques and knowledge of the merits and limitations of the bleeding time test, it is useful for diagnosing hemostasis disorders, guiding their therapy and warning of unexpected bleeding complications in surgical patients. ${ }^{44}$ Stensrud et al. ${ }^{45}$ evaluated the effects of intraoperative hypothermia on blood transfusion during cardiac surgery. They reported that even though no differences in total blood requirements were reported between pa- tients receiving a normothermic cardiopulmonary bypass and those receiving a hypothermic bypass, the hypothermic patients showed an activated partial thromboplastin time that was prolonged by nearly $8 \%$, compared with patients who were actively warmed. No differences were observed in prothrombin time and fibrinogen concentrations. Our study confirms that perioperative warming can significantly reduce bleeding following surgery and that it may be recommended for regular use.

The risk of wound infection in patients undergoing colonic surgery ranges from $9-27 \%{ }^{46}$ and it may be reduced by two-thirds among patients who receive perioperative warming. ${ }^{8,46}$ By extending the warming

Table 5. Wound infection: combined analysis

\begin{tabular}{|c|c|c|}
\hline \multicolumn{3}{|c|}{ Wound infection frequency } \\
\hline & Warming group & Control group \\
\hline Melling et al. ${ }^{14}$ & $13 / 277$ & $19 / 139$ \\
\hline Melling and Leaper ${ }^{18}$ & $0 / 30$ & $1 / 15$ \\
\hline Kurz et al. ${ }^{29}$ & $6 / 104$ & $18 / 96$ \\
\hline
\end{tabular}

Table 6. Trials on postoperative shivering: combined analysis

\begin{tabular}{|c|c|c|}
\hline & Warming group & Control group \\
\hline Zhao et al. ${ }^{21}$ & $0 / 20$ & $6 / 20$ \\
\hline Xu et al. ${ }^{23}$ & $0 / 20$ & $6 / 20$ \\
\hline Vanni et al. ${ }^{24}$ & $0 / 20$ & $5 / 10$ \\
\hline Camus et al. ${ }^{32 *}$ & $1 / 11$ & $9 / 11$ \\
\hline Camus et al. ${ }^{32 \dagger}$ & $2 / 22$ & $7 / 22$ \\
\hline
\end{tabular}

"limb a of trial; †limb b of trial.

Table 7. Trials on blood loss: combined analysis

\begin{tabular}{|c|c|c|}
\hline & Warming group & Control group \\
\hline Zhao et al. ${ }^{21}$ & $112 \pm 80 \mathrm{ml}$ & $350 \pm 145 \mathrm{ml}$ \\
\hline Xu et al. ${ }^{23}$ & $112 \pm 80 \mathrm{ml}$ & $350 \pm 145 \mathrm{ml}$ \\
\hline Persson and Lundberg ${ }^{25}$ & $108 \pm 27 \mathrm{ml}$ & $308 \pm 47 \mathrm{ml}$ \\
\hline Bock et al. ${ }^{27}$ & $635 \pm 507 \mathrm{ml}$ & $1070 \pm 803 \mathrm{ml}$ \\
\hline Schmied et al. ${ }^{11}$ & $1670 \pm 320 \mathrm{ml}$ & $2150 \pm 550 \mathrm{ml}$ \\
\hline
\end{tabular}

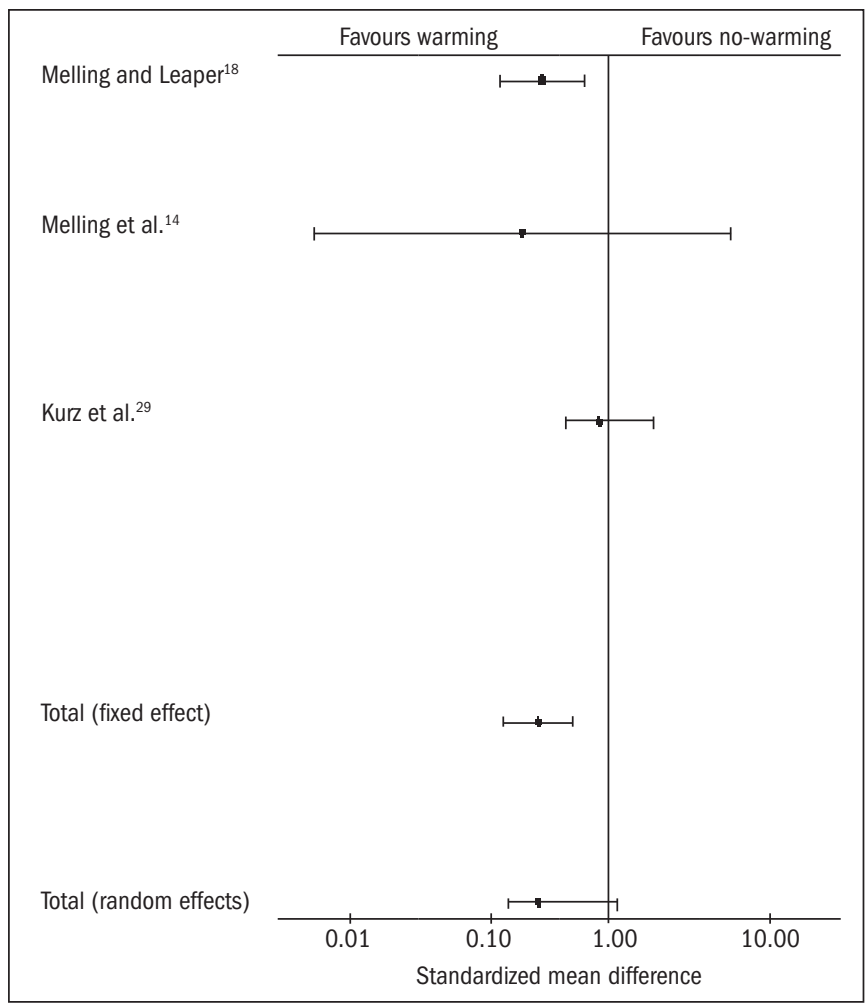

Figure 4. Wound infection: combined analysis of the randomized controlled trials in this review. 
Figure 5. Shivering: combined analysis of the randomized controlled trials in this review.

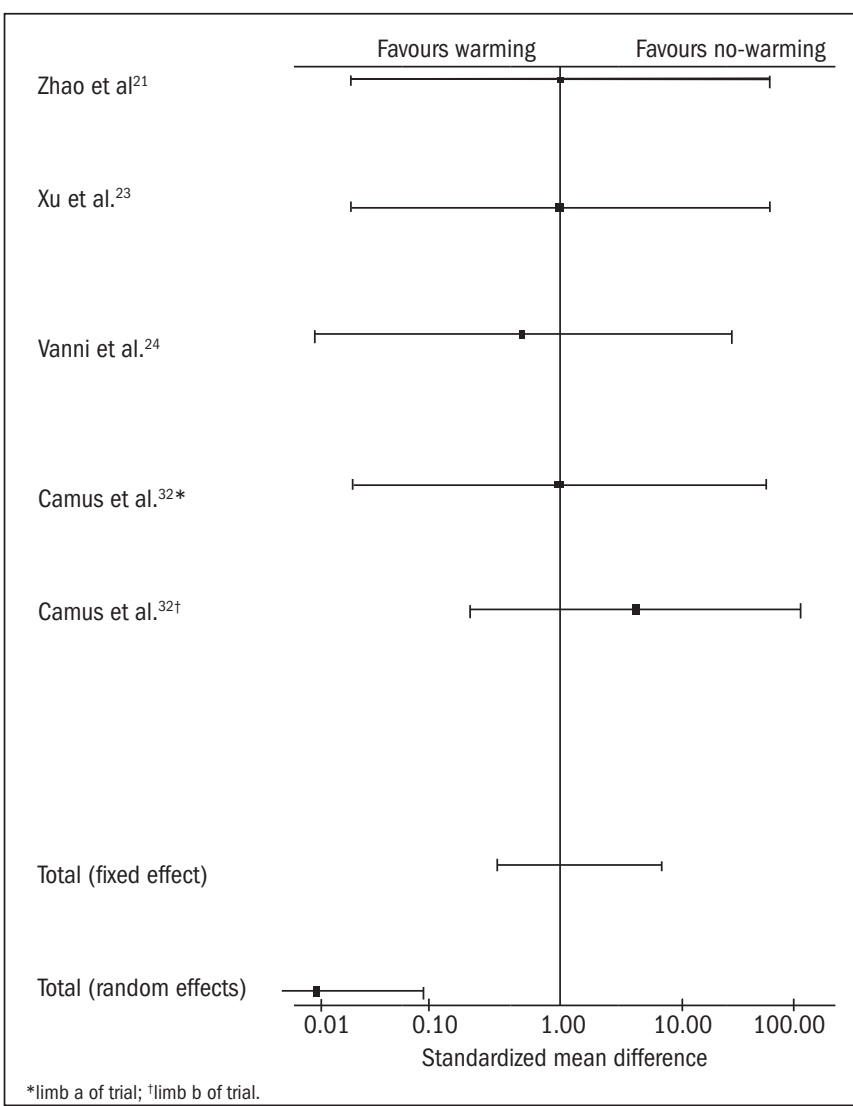

period, to two hours before and after surgery, the incidence of wound infection can be further reduced from $27 \%$ to $13 \%$ and overall complications can be reduced from $54 \%$ to $32 \% .{ }^{17}$ Our review concludes that perioperative warming can significantly reduce the incidence of wound infection.

There was significant heterogeneity among the trials (Chart 1). There may be many reasons for heterogeneity, including combined analysis on trials from various surgical disciplines, combined analysis on trials in which different types of anesthesia (general, spinal or combined epidural and spinal) are used in variable doses and inclusion of trials in which warming was given to different parts of the body. The results from the studies included in this review were also inconsistent. No major multicenter, randomized, controlled trial was reported in the literature. Thus, it was difficult to find high quality, unbiased data for analysis. Nonetheless, this is the only reported systematic review on the role of perioperative warming among surgical patients.

\section{Conclusion}

In conclusion, perioperative warming of surgical patients is effective for reducing postoperative wound pain, wound infection and shivering. Systemic warming of surgical patients is also associated with less perioperative blood loss, by preventing hypothermia-induced coagulopathy. Perioperative warming may be given routinely to all patients in various surgical disciplines in order to counteract the consequences of hypothermia.

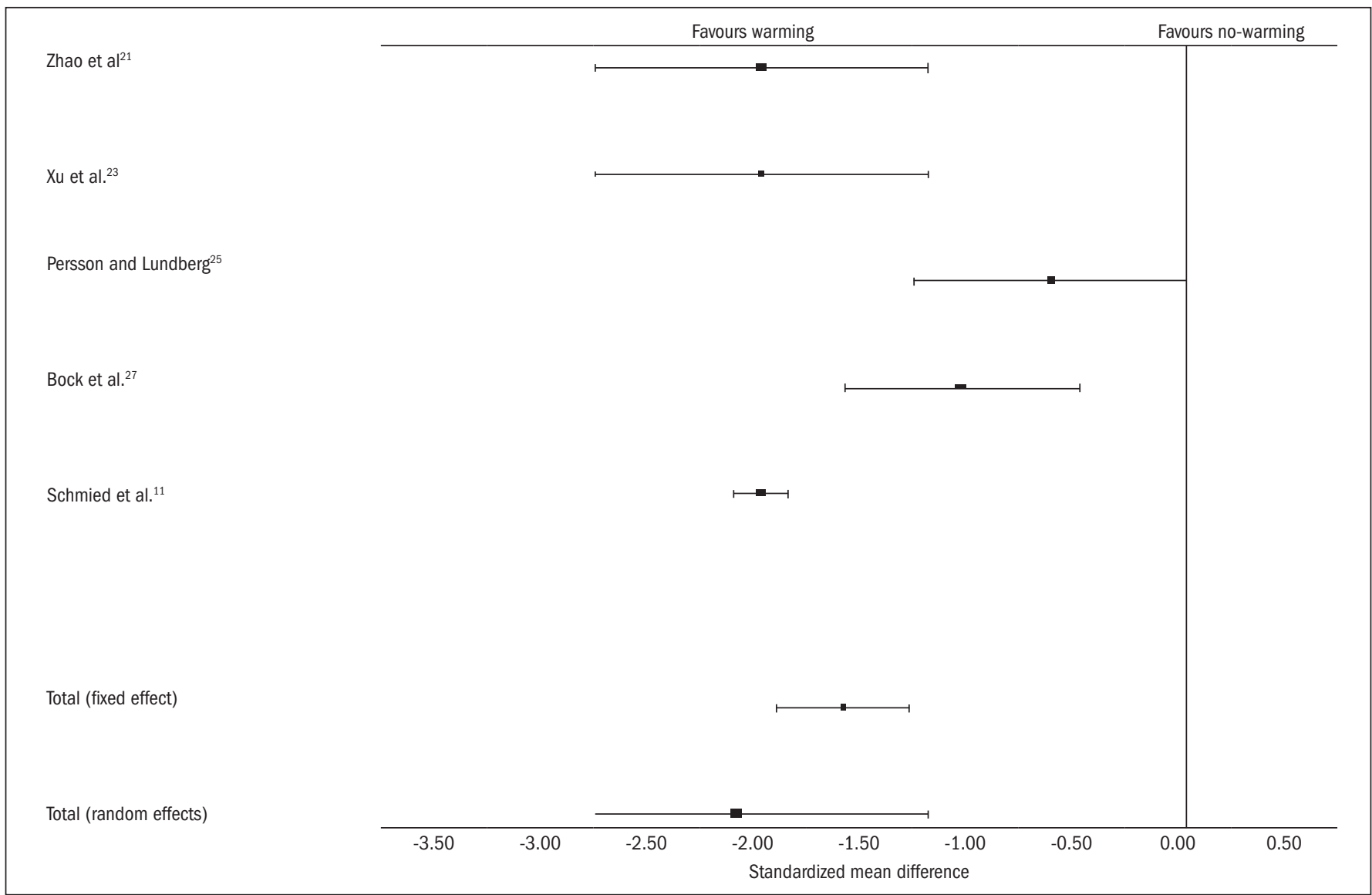

Figure 6. Blood loss: combined analysis of the randomized controlled trials in this review. 


\section{References}

1. Buggy DJ, Crossley AW. Thermoregulation, mild perioperative hypothermia and postanaesthetic shivering. Br J Anaesth. 2000;84(5):615-28.

2. Morley-Forster PK. Unintentional hypothermia in the operating room. Can Anaesth Soc J. 1986;33(4):515-28.

3. Bone RC, Balk RA, Cerra FB, et al. Definitions for sepsis and organ failure and guidelines for the use of innovative therapies in sepsis. The ACCP/SCCM Consensus Conference Committee. American College of Chest Physicians/Society of Critical Care Medicine. Chest. 1992;101(6):1644-55.

4. Slotman GJ, Jed EH, Burchard KW. Adverse effects of hypothermia in postoperative patients. Am J Surg. 1985;149(4):495-501.

5. Sessler DI. Mild perioperative hypothermia. N Engl J Med. 1997;336(24):1730-7.

6. Sessler DI. Complications and treatment of mild hypothermia. Anesthesiology. 2001;95(2):531-43.

7. Sessler DI. Consecuencias y prevención de la hipotermia intraoperatoria moderada [Consequences and prevention of mild intraoperative hypothermia]. Rev Esp Anestesiol Reanim. 1997;44(2):45-6

8. Kurz A, Sessler DI, Lenhardt R. Perioperative normothermia to reduce the incidence of surgical-wound infection and shorten hospitalization. Study of Wound Infection and Temperature Group. N Engl J Med. 1996;334(19):1209-15.

9. Just B, Trévien V, Delva E, Lienhart A. Prevention of intraoperative hypothermia by preoperative skin-surface warming. Anesthesiology. 1993;79(2):214-8.

10. Heier T, Caldwell JE, Sessler DI, Miller RD. Mild intraoperative hypothermia increase duration of action and spontaneous recovery of vecuronium blockade during nitrous oxide-isoflurane anesthesia in humans. Anesthesiology. 1991;74(5):815-9.

11. Schmied H, Kurz A, Sessler DI, Kozek S, Reiter A. Mild hypothermia increases blood loss and transfusion requirements during total hip arthroplasty. Lancet. 1996;347(8997):289-92.

12. Frank SM, Fleisher LA, Breslow MJ, et al. Perioperative maintenance of normothermia reduces the incidence of morbid cardiac events. A randomized clinical trial. JAMA. 1997;277(14):1127-34.

13. Kurz A, Sessler DI, Narzt E, et al. Postoperative hemodynamic and thermoregulatory consequences of intraoperative core hypothermia. J Clin Anesth. 1995;7(5):359-66.

14. Melling AC, Ali B, Scott EM, Leaper DJ. Effects of preoperative warming on the incidence of wound infection after clean surgery: a randomised controlled trial. Lancet. 2001;358(9285):876-80.

15. Hynson JM, Sessler DI, Moayeri A, McGuire J, Schroeder M. The effects of preinduction warming on temperature and blood pressure during propofol/nitrous oxide anesthesia. Anesthesiology. 1993;79(2):219-28; discussion 21A-22A.

16. Rasmussen $\mathrm{YH}$, Leikersfeldt $\mathrm{G}$, Drenck NE. Forced-air surface warming versus oesophageal heat exchanger in the prevention of peroperative hypothermia. Acta Anaesthesiol Scand. 1998:42(3):348-52.

17. Wong PF, Kumar S, Bohra A, Whetter D, Leaper DJ. Randomized clinical trial of perioperative systemic warming in major elective abdominal surgery. Br J Surg. 2007:94(4):421-6.

18. Melling $A C$, Leaper $D J$. The impact of warming on pain and wound healing after hernia surgery: a preliminary study. J Wound Care. 2006;15(3):104-8.

19. Kim JY, Shinn H, Oh YJ, Hong YW, Kwak HJ, Kwak YL. The effect of skin surface warming during anesthesia preparation on preventing redistribution hypothermia in the early operative period of off-pump coronary artery bypass surgery. Eur J Cardiothorac Surg. 2006;29(3):343-7.

20. Cavallini M, Baruffaldi Preis FW, Casati A. Effects of mild hypothermia on blood coagulation in patients undergoing elective plastic surgery. Plast Reconstr Surg. 2005;116(1):316-21; discussion 322-3.

21. Zhao J, Luo AL, Xu L, Huang YG. Forced-air warming and fluid warming minimize core hypothermia during abdominal surgery. Chin Med Sci J. 2005;20(4):261-4.

22. Scheck T, Kober A, Bertalanffy $P$, et al. Active warming of critically ill trauma patients during intrahospital transfer: a prospective, randomized trial. Wien Klin Wochenschr. 2004:116(3):94-7.

23. Xu L, Zhao J, Huang YG, Luo AL. [The effect of intraoperative warming on patient core temperature]. Zhonghua Wai Ke Za Zhi. 2004;42(16):1010-3.

24. Vanni SM, Braz JR, Módolo NS, Amorim RB, Rodrigues GR Jr. Preoperative combined with intraoperative skin-surface warming avoids hypothermia caused by general anaesthesia and surgery. J Clin Anesth. 2003;15(2):119-25

25. Persson K, Lundberg J. Perioperative hypothermia and postoperative opioid requirements. Eur J Anaesthesiol. 2001;18(10):679-86.

26. El-Rahmany HK, Frank SM, Schneider GM, et al. Forced-air warming decreases vasodilator requirement after coronary artery bypass surgery. Anesth Analg. 2000;90(2):286-91
27. Bock M, Müller J, Bach A, Böhrer H, Martin E, Motsch J. Effects of preinduction and intraoperative warming during major laparotomy. Br J Anaesth. 1998;80(2):159-63.

28. Wongprasartsuk P, Konstantatos A, McRae R. The effect of forced air warming on postoperative oxygen consumption and temperature in elective orthopaedic surgery. Anaesth Intensive Care. 1998;26(3):267-71.

29. Kurz A, Sessler DI, Lenhardt R. Perioperative normothermia to reduce the incidence of surgical-wound infection and shorten hospitalization. Study of Wound Infection and Temperature Group. N Engl J Med. 1996;334(19):1209-15.

30. Frank SM, Higgins MS, Breslow MJ, et al. The catecholamine, cortisol, and hemodynamic responses to mild perioperative hypothermia. A randomized clinical trial. Anesthesiology. 1995;82(1):83-93.

31. Frank SM, Beattie C, Christopherson $\mathrm{R}$, et al. Unintentional hypothermia is associated with postoperative myocardial ischemia. The Perioperative Ischemia Randomized Anesthesia Trial Study Group. Anesthesiology. 1993;78(3):468-76.

32. Camus $\mathrm{Y}$, Delva $\mathrm{E}$, Just $\mathrm{B}$, Lienhart A. Leg warming minimizes core hypothermia during abdominal surgery. Anesth Analg. 1993;77(5):995-9.

33. Grocott HP, Mathew JP, Carver EH, et al. A randomized controlled trial of Arctic Sun Temperature Management System versus conventional methods for preventing hypothermia during off-pump cardiac surgery. Anesth Analg. 2004;98(2):298-302.

34. Winkler $\mathrm{M}$, Akça 0 , Birkenberg $\mathrm{B}$, et al. Aggressive warming reduces blood loss during hip arthroplasty. Anesth Analg. 2000;91(4):978-84.

35. Leben J, Tryba M, Kurz-Müller K, Schregel W. Prävention intraoperativer Hypothermie bei Kindern [Prevention of intraoperative hypothermia in children]. Anaesthesist. 1998;47(6):475-8.

36. Hofer CK, Worn M, Tavakoli R, et al. Influence of body core temperature on blood loss and transfusion requirements during off-pump coronary artery bypass grafting: a comparison of 3 warming systems. J Thorac Cardiovasc Surg. 2005;129(4):838-43.

37. Matsuzaki Y, Matsukawa T, Ohki K, Yamamoto Y, Nakamura M, Oshibuchi T. Warming by resistive heating maintains perioperative normothermia as well as forced air heating. Br J Anaesth. 2003;90(5):689-91.

38. Macario A, Dexter F. What are the most important risk factors for a patient's developing intraoperative hypothermia? Anesth Analg. 2002;94(1):215-20, table of contents.

39. Hildebrand F, Giannoudis PV, van Griensven M, Chawda M, Pape HC. Pathophysiologic changes and effects of hypothermia on outcome in elective surgery and trauma patients. Am J Surg. 2004;187(3):363-71.

40. Sessler DI. Perioperative heat balance. Anesthesiology. 2000;92(2):578-96.

41. Krause KR, Howells GA, Buhs $\mathrm{CL}$, et al. Hypothermia-induced coagulopathy during hemorrhagic shock. Am Surg. 2000;66(4):348-54.

42. Lynn M, Jeroukhimov I, Klein Y, Martinowitz U. Updates in the management of severe coagulopathy in trauma patients. Intensive Care Med. 2002;28 Suppl 2:S241-7.

43. Valeri CR, MacGregor H, Cassidy G, Tinney R, Pompei F. Effects of temperature on bleeding time and clotting time in normal male and female volunteers. Crit Care Med. 1995;23(4):698-704.

44. Wolberg AS, Meng ZH, Monroe DM 3rd, Hoffman M. A systematic evaluation of the effect of temperature on coagulation enzyme activity and platelet function. J Trauma. 2004;56(6):1221-8.

45. Stensrud PE, Nuttall GA, de Castro MA, et al. A prospective, randomized study of cardiopulmonary bypass temperature and blood transfusion. Ann Thorac Surg. 1999;67(3):711-15

46. Greif R, Akça O, Horn EP, Kurz A, Sessler DI. Supplemental perioperative oxygen to reduce the incidence of surgical-wound infection. Outcomes Research Group. N Engl J Med. 2000;342(3):161-7.

Sources of funding: None

Conflict of interest: None

Date of first submission: December 8, 2008

Last received: September 29, 2009

Accepted: October 01, 2009

Address for correspondence:

Mr Muhammad Shafique Sajic

Surgical Specialist Registrar, Washington Suite

North Wing, Worthing Hospital,

West Sussex. BN11 2DH. United Kingdom

Tel. 01903205111 ext. 4030

Mobile. 07891667608

Fax. 01903285052

E-mail: surgeon1wrh@hotmail.com 